\title{
Local domestication of lactic acid bacteria via cassava beer fermentation
}

Cassava beer, or chicha, is typically consumed daily by the indigenous Shuar people of the Ecuadorian Amazon. This traditional beverage made from cassava tuber (Manihot esculenta) is thought to improve nutritional quality and flavor while extending shelf life in a tropical climate. Bacteria responsible for chicha fermentation could be a source of microbes for the human microbiome, but little is known regarding the microbiology of chicha. We investigated bacterial community composition of chicha batches using Illumina high-throughput sequencing. Fermented chicha samples were collected from seven Shuar households in two neighboring villages in the Morona-Santiago region of Ecuador, and the composition of the bacterial communities within each chicha sample was determined by sequencing a region of the 165 ribosomal gene. Members of the genus Lactobacillus dominated all samples. Significantly greater phylogenetic similarity was observed among chicha samples taken within a village than those from different villages. Community composition varied among chicha samples, even those separated by short geographic distances, suggesting that ecological and/or evolutionary processes, including human-mediated factors, may be responsible for creating locally distinct ferments. Our results add to evidence from other fermentation systems suggesting that traditional fermentation may be a form of domestication, providing endemic beneficial inocula for consumers, but additional research is needed to identify the mechanisms and extent of microbial dispersal. 
3 Alese M. Colehour ${ }^{1,2}$

4 James F. Meadow ${ }^{2}$

5 Melissa A. Liebert ${ }^{1}$

6 Tara J. Cepon-Robins ${ }^{1}$

7 Theresa E. Gildner ${ }^{1}$

8 Samuel S. Urlacher ${ }^{3}$

9 Brendan J.M. Bohannan²

10 J. Josh Snodgrass ${ }^{1}$

11 Lawrence S. Sugiyama ${ }^{1}$

$12{ }^{1}$ Department of Anthropology, University of Oregon, Eugene, OR, USA

$13{ }^{2}$ Institute of Ecology and Evolution, University of Oregon, Eugene, OR, USA

$14{ }^{3}$ Department of Human Evolutionary Biology, Harvard University, Cambridge, MA, USA

15 Corresponding Author: Alese M. Colehour, alese@uoregon.edu; 308 Condon Hall;

161218 University of Oregon; Eugene, OR, 97402

\section{ABSTRACT} the Ecuadorian Amazon. This traditional beverage made from cassava tuber (Manihot esculenta) is thought to improve nutritional quality and flavor while extending shelf life in a tropical climate. Bacteria responsible for chicha fermentation could be a source of microbes for the human microbiome, but little is known regarding the microbiology of chicha. We investigated bacterial community composition of chicha batches using Illumina high-throughput sequencing. Fermented chicha samples were collected from seven Shuar households in two neighboring villages in the Morona-Santiago region of Ecuador, and the composition of the bacterial communities within each chicha sample was determined by sequencing a region of the $16 \mathrm{~S}$ ribosomal gene. Members of the genus Lactobacillus dominated all samples. Significantly greater phylogenetic similarity was observed among chicha samples taken within a village than those from different villages. Community composition varied among chicha samples, even those separated by short geographic distances, suggesting that ecological and/or evolutionary processes, including human-mediated factors, may be responsible for creating locally distinct ferments. Our results add to evidence from other fermentation systems suggesting that traditional fermentation may be a form of domestication, providing endemic beneficial inocula for consumers, but additional research is needed to identify the mechanisms and extent of microbial dispersal.

INTRODUCTION

38 Fermentation converts simple carbohydrates into secondary compounds, including alcohols and lactic acid, and is used by human societies worldwide as a means to improve the flavor, nutritional value, and/or preservation of food and drinks (CampbellPlatt, 1994; van Hylckama Vlieg et al., 2011). Fermentation is mediated by a variety of microorganisms; for example, yeasts convert carbohydrates into carbon dioxide and 
alcohol to produce alcoholic beverages, while Lactobacillus bacteria create lactic acid,

44 the tangy flavor characteristic of food such as sauerkraut and yogurt. Conventional

45 fermentation utilizes commercially available bacteria or yeast for fermentation, often

46 from a single laboratory-isolated strain. In contrast, spontaneous fermentation -sometimes called traditional or wild fermentation -- exposes carbohydrates to diverse microorganisms resident in the environment to cultivate a ferment (Campbell-Platt, 1994; Scott \& Sullivan, 2008; McGee, 2013). Often, diverse communities of bacteria and yeast undergo ecological succession in the fermentation vessel as the community structure changes in response to conditions created by preceding species.

In a liquid-substrate ferment of cassava (Manihot esculenta), lactic-acid bacteria (LAB) dominate throughout the process but specific composition is variable as the bacterial byproducts increase the acidity, shifting the $\mathrm{pH}$ from 6.5 to around 4.5 after 48 hours (Abriba et al., 2012; Tetchi et al., 2012). LAB are commonly associated with nutrient rich-substrates belonging to a range of plants and animals. Sources of bacteria in a lactic-acid ferment could include inocula from the raw material (plant substrate or water), airborne dust, fermentation tools/vessel, or bacteria introduced by humans supervising the fermentation process. Site-specific spontaneous fermentation replicated over long periods of time has been considered a form of microbial domestication, especially in Saccharomyces yeast and LAB (Fay \& Benavides, 2005; Suzzi, 2011; Bachmann et al., 2012). This suggests that ecological processes inherent in spontaneous fermentation, including human-mediated selection, could result in artisanal products unique to a particular region and cultural practice (e.g. lambic ales [Spitaels et al., 2014], Old World wines [Sun, Ma, Hao, Pretorius, \& Chen, 2009], cheeses [Bokulich \& Mills, 2013], and sourdough breads [Scheirlinck et al., 2007]). Domestication of LAB can be demonstrated if human choice (e.g. tuber variety, batch size, fermentation length, and individual flavor preferences), and adaptation to unique environmental fluctuations (e.g. temperature, $\mathrm{pH}$, and disturbance) result in a unique microbial community that is consistent over time.

Chicha is a generic term for traditional fermented beverages produced by indigenous groups throughout the Amazon basin and Andes. It can be made from a variety of starchy plant crops including maize, cassava, and millet. Archaeologists have identified traces of 1600-year-old sprouted maize chicha in 150-liter clay vats in the remains of a pre-Incan civilization in Cerro-Baul, Peru, making it one of the oldest known ferments (Moseley et al., 2005). Today, indigenous Amazonian groups continue to brew chicha (also generically referred to as masato in some regions) from sweet cassava, also called manioc or yuca, a staple tuber cultivar in tropical climates. Chicha from cassava is typically a low alcohol beverage (2-5\%), with a milky consistency and somewhat sour flavor. Amongst Shuar, chicha (nijiamanch' in Shuar) is typically prepared over a 2-3 day period. First, the roots of yuca are peeled, washed, and boiled until soft. Water is then drained off and the root mashed (traditionally on a large wooden platter but now commonly in a large metal pot) with a dedicated pestle, while the brewer masticates pieces of the yuca and periodically spits into the mash. Recipes vary according to the brewer's taste. For example, different locally identified varieties of yuca can be mixed together, or yam (Dioscorea sp.) is sometimes added. The finished mash is placed in a designated vessel to ferment for 1-3 days, depending on preference for sweet (slightly to unfermented) to sour (very fermented) chicha. While traditional fermentation vessels were ceramic, today 3-5 gallon plastic buckets are typically used. Water is then mixed with the fermented mash just prior to serving, with consistency based on desired water to mash content. 
92

93

94

95

96

97

98

99

100

101

102

103

104

105

106

107

108

109

110

111

112

113

114

115

116

117

118

119

120

121

122

123

124

125

126

127

128

129

130

131

132

133

134

135

136

137

138

139

140
First domesticated in neo-tropical lowland South America 8000-10,000 years ago, cassava continues to be a dietary staple across this region for many Amazonian foragerhorticulturalist groups (Piperno, 2011). Fermented cassava beer remains a key component of the diet for many, with fermentation improving bioavailability and synthesis of essential vitamins and minerals (zinc, calcium, iron and magnesium) that may otherwise be lacking (Boonnop et al., 2009; Ahaotu et al., 2011; Dilworth et al., 2013). This is particularly important since chronic nutritional stress among indigenous groups can stunt growth (Blackwell et al., 2009; Piperata et al., 2011). Furthermore, fermentation facilitates decomposition of organic toxins such as naturally occurring cyanides in yuca that cause weakness, hypothyroidism, and paralysis (Lei, Amoa-Awua, \& Brimer, 1999).

Despite the importance and widespread consumption of chicha, no studies to date have characterized the microbial community present in chicha using modern culture-independent techniques. Several groups of lactic-acid bacteria including Lactobacillus spp., have been detected in cassava ferments using culture-dependent methods (Axelsson, 2009; Santos et al., 2012). Other research on similar cassava ferments documented the sharpest decrease in sugar content occurring between 24 and 48 hours, corresponding with increasing mass of LAB reaching peak CFU/g at 72 hours after fermentation is initiated (Tetchi et al., 2012). In culture-dependent sugar metabolism profiling experiments, $90 \%$ of LAB strains isolated from a cassava ferment digest glucose, gluconate, maltose, melibiose, raffinose and sucrose, while less than $10 \%$ of strains fermented esculin, cellobiose, glycerol, mannitol, melizitose and rhamnose (Kostinek et al., 2005). Isolates from cassava fermentation also exhibited high levels of hydrogen peroxide and bacteriocin production, antimicrobial agents produced by LAB antagonistic toward closely related strains (Kostinek et al., 2007) and toward fungal species (Adebayo \& Aderiye, 2010).

Some species of Lactobacillus are considered to be beneficial to human health, given their ability to compete with pathogens, stimulate mucus production, and bind to the lining of the intestinal tract (Kravtsov et al., 2008; Lebeer, Vanderleyden, \& De Keersmaecker, 2008; Turpin et al., 2012). Certain strains also improve the uptake of nutrients by enhancing mineral absorption, promoting host growth factors, and degrading antinutrients (e.g. digestion inhibitors synthesized as a plant's self-defense against herbivores) (Turpin et al., 2010). Commercially-isolated Lactobacillus strains are commonly added to pasteurized dairy products such as yogurt or sold in capsule form as an increasingly popular solution for an array of common health problems, including irritable bowel syndrome and other conditions related to chronic inflammation of the intestinal tract (Allgeyer, Miller, \& Lee, 2010; Ranadheera, Baines, \& Adams, 2010; Yang \& Sheu, 2012). In contrast, a few species of LAB are also known producers of biogenic amines in vegetable ferments but these are only toxic in high concentrations when they accumulate in ferments lasting several weeks (Halász et al., 1994). Traditional amylaceous (starch-based) ferments such as chicha may contain novel strains of Lactobacillus that might be a source of microbes in indigenous populations (Aro, 2008; Chelule, Mokoena, \& Gqaleni, 2010; Chelule et al., 2010; van Hylckama Vlieg et al., 2011). Much is known about the health benefits of certain strains but these cannot be generalized across all species of LAB since specific characteristics can vary dramatically (Makarova et al., 2006; Turpin et al., 2010).

Just as in any ecosystem, bacterial communities in fermented foods are shaped by a variety of ecological processes, including environmental selection and dispersal, that select for a subset of potential inhabitants from a metacommunity (a set of 
141 communities linked by dispersal of multiple, interacting species). Lactic-acid bacteria in

142 spontaneous ferments have the unique ability to survive both nutrient saturation and

143 starvation, suggesting that some Lactobacilli are well adapted to fermentation of food

144 both inside and outside the gastrointestinal tract (Ganesan, Dobrowolski, \& Weimer,

145 2006; Suzzi, 2011; van Hylckama Vlieg et al., 2011). Recent research shows spatial

146 diversification of bacteria and yeast populating artisan cheese cultures that correlate

147 with those of specific surfaces in the processing facility (Bokulich \& Mills, 2013), hinting

148 at the possibility that microbial communities undergo geographic divergence in human-

149 mediated ecosystems. However, it is unclear whether bacterial community composition

150 in a small-batch spontaneous ferment shows spatial diversification that would suggest

151 incidental domestication.

152

To examine geographic variation in spontaneous ferments, we collaborated with an indigenous group of Shuar (as part of the Shuar Health and Life History Project

154 [http://www.bonesandbehavior.org/shuar/]) engaged in a forager-horticulturalist lifestyle

155

156

157

158

159

160 in the remote Cross-Cutucú region of the Ecuadorian Amazon. We assessed phylogenetic similarity of bacterial communities in chicha batches from households in two villages to determine whether: 1) a ferment from one house was significantly different than ferments from neighboring households in the same village, and; 2) ferments from different households in the same village were more similar to each other than to batches from households in a different village.

\section{MATERIALS \& METHODS}

162 Population and Location

163 All samples were collected in the Cross-Cutucú region of the neo-tropical lowlands of 164 southeastern Ecuador, which lies east of the Cutucú Mountains along the Morona river 165 drainage. This region has an annual rainfall of more than 4,000 mm (158 inches) and average daytime temperatures of $29 \mathrm{C}$ (85 F) (Kricher, 1999).

The Shuar of this region are an indigenous forager-horticulturalist group who live primarily in small riverine villages. They are a natural fertility population and traditionally lived in scattered matrilocal household clusters in traditional thatch-wall, earthen-floor houses (Karsten, 1935; Descola, 1996; Rubenstein, 2001), although plank houses with tin roofs are becoming more common. Present day subsistence remains based on horticulture, fishing, hunting and gathering, yet they are currently experiencing increasingly rapid infrastructure development and market integration as a result of regional economic development (Blackwell et al., 2009; Liebert et al., 2013). However the villages in the present study subsist with limited daily access to markets or exposure to economic development. Rates of infectious disease remain high throughout this population, accounting for 15\% adult mortality in 2008 (World Health Organization, 2011; McDade et al., 2012). Further, Cepon-Robins and colleagues (2013) reported that $65 \%$ of the population in this particular region is infected with parasitic worms, with even higher prevalence among children. Stunting among children is a common public health concern, and is relevant to ongoing studies investigating metabolic health in the context of economic transitioning populations (Santos, Coimbra \& Escobar, 2003; Foster et al., 2005; Orellana et al., 2009; Blackwell et al., 2009; Liebert et al., 2013) making nutritionrelated health research a high priority in this region.

\section{Sample Collection}

186 We collected samples in two villages in the Cross-Cutucú region of Morona Santiago, 187 Ecuador. Village 1 (V1; pop. 50) is located approximately one to four hours by motorized 
188

189

190

191

192

193

194

195

196

197

198

199

200

201

202

203

204

205

206

207

208

209

210

211

212

213

214

215

216

217

218

219

220

221

222

223

224

225

226

227

228

229

230

231

232

233

canoe (depending on water levels) from the nearest port with road access. A nearby spring located upstream from the village provides water for bathing and cooking. Village 2 (V2; pop. 400) is located twenty-minutes by foot from V1 (including a bridgeless river crossing). Water is pumped from the river to a reserve that flows through pipes to some houses. In both villages, each household has their own chicha ferment, containing brews that are commonly maintained by the resident women. New batches are produced every 3-5 days or as needed.

We collected $2 \mathrm{~mL}$ of mature chicha from five households in $\mathrm{V} 1$ and two households in V2, during August 2012 (sample volume was limited due to limited freezer space on site). Over a period of two weeks, we collected samples from each of these seven ferments up to three times, each representing independent batches (with a shared starter culture). Fermentation maturity of samples was confirmed with litmus paper ensuring a pH range between 4.0-4.5 (Luedeking \& Piret, 1959; Santos et al., 2012). We sampled $300 \mathrm{~mL}$ of spring water (concentrated on a 0.45 micron pore, cellulose acetate filter) that residents in V1 use to prepare chicha. We were unable to collect water from V2 due to equipment malfunction. All samples were immediately frozen $(-20 \mathrm{C})$ before being transported and stored at the University of Oregon until they were processed. All samples were examined under a light microscope for evidence of helminth eggs or macrophages.

\section{Ethics Statement}

This study was conducted in Shuar villages located within Canton Tiwintza, Morona Santiago, Ecuador. Research for the Shuar Health and Life History project was authorized in a letter provided by the Federación Interprovincial de Centros Shuar (FICSH). No human data was gathered as part of this project, and the bacterial data gathered was purged of human mitochondrial sequences by removing all sequences classified within the Order Rickettsiales before archiving. Genetic material resulting from this research will never be used for human DNA research or commercial cell-line patenting.

\section{Bacterial DNA Extraction and Sequencing}

Whole genomic DNA was extracted from all samples using MO BIO Power Plant Pro kit including phenol separation solution step (MO BIO Laboratories, Carlsbad, CA) and amplified on the V4 region of the 16S rRNA (F515/R806 primer combination: 5'GTGCCAGCMGCCGCGGTAA-3', 5'-TACNVGGGTATCTAATCC-3') (Caporaso et al., 2010). DNA amplifications were performed in triplicate and pooled prior to sequencing. The reverse primer included a 12 bp Golay barcode for demultiplexing in downstream analysis. PCR conditions followed Caporaso et al. (2010). Amplicons were purified using gel electrophoresis and the MO BIO UltraClean GelSpin DNA extraction kit. Equal amounts of purified amplicons from each sample were pooled and sent to the Dana Farber Cancer Institute Molecular Biology Core Facility (http://www.dana-farber.org), to be sequenced on the Illumina MiSeq platform using a paired-end $250 \mathrm{bp}$ protocol. All sequences have been deposited in the MG-RAST archive under accession numbers 4545634.3-4545652.3.

\section{Sequence Processing and Statistical Analysis}

Sequence processing was conducted in QIIME (Caporaso, Kuczynski, \& Stombaugh, 2010) using MacQiime (version 1.6.0, http://www.wernerlab.org/software/macqiime; QIIME, RRID:OMICS_01521). Quality filtered forward reads (Phred score>20; 250bp) 
234 were binned with barcodes corresponding to the respective sample IDs. Operational

235 taxonomic units (OTUs) were assigned at $99 \%$ genetic similarity. Representative OTU

236 sequences were aligned to the Greengenes database (October 2012 version) and

237 assigned taxonomic nomenclature with an RDP classifier. We rarified all samples to

23819,000 sequences for even sampling depth; two samples significantly below that

239 threshold were omitted from further analysis.

240 We also conducted a manual BLAST search against the NCBI 16S isolate database for the top 10 OTUs for exploratory purposes (NCBI BLAST, RRID:nIx_84530). We included these species-level NCBI database matches for visualization and reporting. Results from OTU clustering matched to the Greengenes database using an RDP classifier within the QIIME pipeline were used for all analysis purposes.

Community similarity was calculated in two different ways: with the phylogenybased UniFrac metric (unweighted), and by calculating the number of OTUs shared between samples. Unweighted UniFrac uses phylogeny-based branch lengths generated from our rarified dataset, comparing their fractions between samples to quantify dissimilarity between communities without regard for species abundance. We determined if differences were significant using PERMANOVA (Adonis method) in QIIME. Using the UniFrac matrix, we generated a PCoA plot in QIIME and included it as Figure 4. We then used the QIIME generated OTU table to conduct a one-way ANOVA in SPSS (SPSS, RRID:rid_000042, version 20.0.0) to investigate differences in the number of shared OTUs across households and across villages (Figure 3 ).

\section{RESULTS}

We generated a total of 1,055,214 barcoded sequences 249 base pairs in length. Sequences were quality filtered and rarefied to 19,000 OTUs per sample. The nineteen samples used for analysis represent one to three chicha batches from each of 7 different households (five from Village 1 and two from Village 2). Clustering of OTUs revealed that members of the genus Lactobacillus dominated the bacterial communities in all samples (Figure 1). Of the ten most abundant OTUs across samples, nine were Lactobacillus; the other was an Acetobacter. These 10 OTUs each represented $>1 \%$ of each sample, collectively accounting for $71 \%$ of the sequences in all samples. The top two most abundant species predicted through a BLAST search on the NCBI database, L. acidophilus and $L$. reuteri, account for $51 \%$ of the entire dataset (Figure 2). Two of the most abundant Lactobacillus OTUs were less than $98 \%$ similar to existing isolates in the $\mathrm{NCBI}$ database, potentially suggesting the presence of previously undescribed taxa, though we were not able to assess this with short $16 \mathrm{~S}$ sequence reads. Figure 2 provides a descriptive table of the most abundant species, as predicted by a BLAST search in the NCBI 16S isolate database, as well as an isolate source habitat for each.

The bacterial communities detected in water samples had higher phylum level diversity than chicha (Supplemental Material; 127,558 OTUs per sample). Whereas Lactobacillaceae dominated chicha, Delftia acidovorans (NC_010002), a member of the Comamonadaceae first isolated from a sewage treatment plant (Schleheck et al., 2004), was the most abundant OTU encountered in water (Supplemental Material; 18.4\%). The bacteria most commonly shared between water and chicha were species within the genus Acetobacter. This clade oxidizes alcohol and sugar to create acetic acid and some members of this genus have been found in traditional balsamic vinegar production (Gullo, De Vero, \& Giudici, 2009). Overall, community composition of chicha was very different from water, indicating the bacterial population is driven by more than just the water source. 

(64\%) and chloroplast (22\%) clusters (Figure 1), presumably from the plant's genetic material before it is degraded during boiling and fermentation. We opted to leave chloroplast sequences in the dataset since levels were negligible in mature ferments $(<1 \%)$, and the abundance in the unfermented sample is potentially informative (Supplemental Material). Low levels of Lactobacillus are present in the unfermented sample (1.5\%) but the increase in Lactobacillus sequences in the finished product is accompanied by a dramatic reduction in the OTUs found in the unfermented sample.

Since this population is known to carry a high parasite burden (Cepon-Robins et al., 2013), we examined our samples for evidence of viable parasites. No helminth eggs or macrophages were detected in the samples. However, the samples underwent two freeze-thaw cycles before microscopic examination, which is known to reduce visibility of parasites. Additional research is needed before we can present any evidence that fermentation affects the transmission of parasites.

Bacterial communities in chicha were significantly different across the two villages (Figure 4; $F_{1,12}=1.11, R^{2}=0.08 ; p=0.038$; from PERMANOVA on unweighted UniFrac dissimilarity matrix), but they were not significantly different across households within a village $\left(F_{5,8}=0.38, p=0.73\right)$. Water samples were significantly different from the chicha samples (Supplemental Material: $F_{1,17}=8.25, p=0.005$ ). More OTUs were shared between households within a village than across villages (Figure 3: $M_{\text {DifferentVillage }}=7.44$, $\left.M_{\text {Samevillage }}=8.31, F_{1,89}=4.11, p=0.046\right)$, but batches from the same household did not have more OTUs in common than they did with other batches from houses in the same village $\left(M_{\text {DifferentHouse }}=7.93, M_{\text {SameHouse }}=8.27, F_{1,89}=0.28, p=0.60\right)$.

\section{DISCUSSION}

Humans continuously and intimately interact with microorganisms. This study demonstrates that spontaneous, or traditional, fermentation promotes a diversity of microorganisms, including some Lactobacillus strains that may potentially interact with human and environmental microbes during production and consumption. Spontaneous fermentation and consumption of its product can be a microbial exchange between the environment and the human microbiome that is mediated by human behavior, abiotic factors, and random chance (Figure 5). The microbial community of chicha could be initiated from a variety of sources including saliva added to each new batch, tools and vessels that may contain remnants or bacterial residue from a previous ferment, the water added to thin the cassava mash, the substrate of the raw material, or the household and airborne environment. In turn, ferments by lactic acid bacteria are consumed and become a potential source of microbes for the human body. While not all LAB confer benefits, many Lactobacilli have been positively associated with human health. (Dethlefsen, McFall-Ngai, \& Relman, 2007; Costello et al., 2009; Spor, Koren, \& Ley, 2011; The Human Microbiome Project Consortium, 2012; Linnenbrink et al., 2013;). All of the numerically dominant OTUs we detected in chicha were related to Lactobacillus species that have also been reported in the human oral and fecal microbiome (Dewhirst et al., 2010). Our conclusions are based on short reads so a much more detailed study is necessary to determine if any of the Lactobacillus taxa we detected might confer health benefits or even successfully assimilate into the human microbiome.

Lactic-acid bacteria are found in association with nutrient rich environments on animals and plants. While some strains produce biogenic amines that can be detrimental to human health (Halász et al., 1994), other research highlights positive 
effects of consuming LAB in moderate amounts. In the human intestinal tract, high rates

331 of adhesion to the mucus membrane allow for direct interface with the human intestine,

332 and have been shown to protect against pathogens, modulate immune response, and

333 promote mucus secretions to soothe the intestinal lining. In addition, lactic-acid bacteria

334 provide digestion assistance, improving vitamin and mineral bioavailability while

335 degrading antinutrients and other phytotoxins such as cyanide (Campbell-Platt, 1994;

336 Westby, Reilly, \& Bainbridge, 1997; Aro, 2008; Chelule, Mokoena, \& Gqaleni, 2010;

337 Turpin et al., 2010).

338 To better understand the spatial and household variability in microbial community

339

340

341

342

343

344

345

346

347

348

349

350

351

352

353

354

355

356

357

358

359

360 composition in spontaneous ferments, we were interested in knowing if bacterial composition showed phylogenetic divergence over geographic space. We observed that the bacterial communities in chicha were more similar within a village than between villages $(p=0.038)$. This variation could result from a combination of mechanisms, including distance-limited dispersal, stochastic succession (including horizontal genetransfer), and human-mediated selection. Since our sample size is modest, we recognize that the significant difference we found could be driven by one particular sample (Figure 1) but our Adonis results are supported by our ANOVA analysis showing significant within-village OTU overlaps, strengthening evidence for higher rates of bacterial similarity within a village.

We observed that chicha is generously shared with neighbors within a village so it is not surprising that we did not see significant phylogenetic dissimilarity at the household level. Dispersal between chicha ferments could occur if starter cultures are mixed or if a brewer contributes saliva to her neighbor's chicha. Based on ethnographic evidence, oral microbiome swapping is actually more likely to happen during consumption, when the drinking cup, pilchis, are passed around a social gathering and dipped repeatedly into the fermentation vessel after each individual takes a drink. Distance and geographic barriers (e.g. a bridgeless river in our case) limit social interaction and subsequently the opportunity for dispersal between the two villages, which may partially explain the observed variation in the bacterial community (Bokulich \& Mills, 2013; Linnenbrink et al., 2013).

Each new chicha batch represents a unique opportunity for succession, which could be contingent on the order and frequency of species arrival. In addition, competition between microbes, abiotic conditions, rate of horizontal gene transfer, and random chance could all shape the communities within each chicha vessel. The water source used in the fermentation vessel (V1: hauled in vessels from a spring; V2: piped to outdoor spigots near houses from a reservoir) may represent a source of either facilitative or competing microbes that could influence the final composition of the ferment. Since households within a village rely primarily on the same water source, this could help explain why chicha is more similar within a village but not within an individual household. It is possible that soil differences between gardens or village areas could yield variation in the plant-associated bacteria present on the raw material, but this seems unlikely since the raw material is peeled and boiled in preparation for fermentation, although contamination of pre-boiled product via tools and skin is possible.

Differences in ferment cultivation practice between the two villages may also contribute to variation (human-mediated selection). Expressions among the Shuar such as "the prettiest girls makes the best chicha" suggest individuality, personal preferences, or oral hygiene could also play a role in the cultivation of this ferment. The addition of saliva could be another source of variance, particularly if genetic or lifestyle differences contribute to distinct oral microbiome communities. Finally, any bacteria leftover in the 
379 fermentation vessel or on the tools used to make the mash may act as a starter culture

380 for each new batch. Although beyond the scope of this article, it is tempting to speculate 381 that distinct bacterial communities may be maintained over time, and that the 382 combination of these factors suggest an example of microbial domestication.

383 These three processes, human-mediated selection, distance-limited dispersal, 384 and stochastic variance help explain the cross-sectional bacterial community variation 385 we observed in chicha. If site-specific bacteria communities are consistent over time this 386 would indicate that the ferment may be a player in a co-evolutionary relationship with 387 human and environmental microbes (Figure 5), but future work with higher sample size 388 is necessary to explore these ideas in greater depth.

\section{ACKNOWLEDGEMENTS}

390 We thank the Shuar community members for their collaboration and hospitality. Lab 391 work and analysis were completed in collaboration with various members in Dr. Brendan Bohannan and Dr. Jessica Green's labs in the Institute of Ecology and Evolution, University of Oregon (UO) including Lucas Nebert, Ashley Bateman, Adam Altrichter, Ann Womack, and Adam Burns. We would also like to acknowledge two anonymous reviewers for providing us with thoughtful feedback on a previous version of this manuscript.

\section{REFERENCES}

Abriba, C., Henshaw, E. E., Lenox, J., Eja, M., Ikpoh, I. S., \& Agbor, B. E. 2012. Microbial succession and odour reduction during the controlled fermentation of cassava tubers for the production of "foofoo", a staple food consumed popularly in Nigeria. Journal of Microbiology and Biotechnology Research 2(4):500-506.

Adebayo, C., \& Aderiye, B. 2010. Antifungal activity of bacteriocins of lactic acid bacteria from some nigerian fermented foods. Research Journal of Microbiology 5(11):1070-1082.

Ahaotu, I., Ogueke, C., \& Owuamanam, C. 2011. Protein improvement in gari by the use of pure cultures of microorganisms involved in the natural fermentation process. Pakistan Journal of Biological Sciences 14(20):933-938.

Allgeyer, L. C., Miller, M. J., \& Lee, S.-Y. 2010. Drivers of liking for yogurt drinks with prebiotics and probiotics. Journal of Food Science 75(4):S212-S219.

Aro, S. 2008. Improvement in the nutritive quality of cassava and its by-products through microbial fermentation. African Journal of Biotechnology. Academic Journals (Kenya).

Axelsson, L. 2009. "Lactic acid bacteria: classification and physiology". Lactic acid bacteria: microbiological and functional aspects 1-66.

Bachmann, H., Starrenburg, M. J. C., Molenaar, D., Kleerebezem, M., \& van Hylckama Vlieg, J. E. T. 2012. Microbial domestication signatures of Lactococcus lactis can be reproduced by experimental evolution. Genome research 22(1):115-24.

Blackwell, A. D., Pryor, G., Pozo, J., Tiwia, W., \& Sugiyama, L. S. 2009. Growth and market integration in Amazonia: a comparison of growth indicators between Shuar, Shiwiar, and nonindigenous school children. American Journal of Human Biology 21(2):161-171.

Blaser, M. 2011. Stop the killing of beneficial bacteria. Nature 476:393-394.

Bokulich, N. A., \& Mills, D. A. 2013. House Microbiome Drives Microbial Landscapes of Artisan Cheesemaking Plants. Applied and environmental microbiology 79(17): 5214-5223.

Boonnop, K., Wanapat, M., Nontaso, N., \& Wanapat, S. 2009. Enriching Nutritive Value of Cassava Root (October):629-633.

Campbell-Platt, G. 1994. Fermented foods - a world perspective. Food Research International 27(3):253-257.

Caporaso, J. G., Lauber, C. L., Walters, W. A., Berg-lyons, D., Lozupone, C. A., Turnbaugh, P. J., Fierer, N., \& Knight, R. 2010. Global patterns of 16S rRNA diversity at a depth of millions of sequences per sample. Proceedings of the National Academy of Sciences 108: 4516-4522. 
Caporaso, J., Kuczynski, J., \& Stombaugh, J. 2010. QIIME allows analysis of high- throughput community sequencing data. Nature 7(5):335-336.

Cepon-Robins, T. J., Gildner, T. E., Liebert, M. A., Colehour, A. M., Urlacher, S. S., Snodgrass, J. J., Madimenos, F. C., \& Sugiyama, L. S. 2013. The Shuar health and life history project: market integration, avoidance behavior, and intestinal helminths among an indigenous lowland Ecuadorian population. American Journal of Human Biology 25:253-254.

Chelule, P. K., Mbongwa, H. P., Carries, S., \& Gqaleni, N. 2010. Lactic acid fermentation improves the quality of amahewu, a traditional South African maize-based porridge. Food Chemistry 122(3):656661.

Chelule, P., Mokoena, M., \& Gqaleni, N. 2010. Advantages of traditional lactic acid bacteria fermentation of food in Africa. Current Research,Technology Topics in Applied Microbiology and Microbial Biotechnology (Spain) 2:1160-1167.

Cho, I., \& Blaser, M. J. 2012. The human microbiome: at the interface of health and disease. Nature Reviews Genetics 13(4):260-270.

Costello, E. K., Lauber, C. L., Hamady, M., Fierer, N., Gordon, J. I., \& Knight, R. 2009. Bacterial community variation in human body habitats across space and time. Science (New York, N.Y.) 326(5960):1694-7.

Descola, P. 1996. The spears of twilight: life and death in the Amazon Jungle. New York: New Press.

Dethlefsen, L., McFall-Ngai, M., \& Relman, D. A. 2007. An ecological and evolutionary perspective on human - microbe mutualism and disease. Nature 449(7164):811-818.

Dewhirst, F. E., Chen, T., Izard, J., Paster, B. J., Tanner, A. C. R., Yu, W. H., Lakshmanan, A., \& Wade, W. G. 2010. The human oral microbiome. Journal of bacteriology 192(19):5002-17.

Dilworth, L. L., Brown, K. J., \& Asemota, H. N. 2013. Bioavailability of essential minerals from staples commonly consumed in the tropics. Journal of Food Research 2(2):83-91.

Fay, J. C., \& Benavides, J. a. 2005. Evidence for domesticated and wild populations of Saccharomyces cerevisiae. PLoS genetics 1(1):66-71.

Foster, Z., Byron, E., Reyes-García, V., Huanca, T., Vadez, V., Apaza, L., Pérez, E., Tanner, S., Gutierrez, Y., Sandstrom, B., et al. 2005. Physical growth and nutritional status of Tsimane'Amerindian children of lowland Bolivia. American Journal of Physical Anthropology 126(3):343-351.

Ganesan, B., Dobrowolski, P., \& Weimer, B. C. 2006. Identification of the leucine-to-2-methylbutyric acid catabolic pathway of Lactococcus lactis. Applied and environmental microbiology 72(6):4264-73.

Gullo, M., De Vero, L., \& Giudici, P. 2009. Succession of selected strains of Acetobacter pasteurianus and other acetic acid bacteria in traditional balsamic vinegar. Applied Environmental Microbiology 75:2585-2589.

Halász, A., Baráth, Á., Simon-Sarkadi, L., \& Holzapfel, W. 1994. Biogenic amines and their production by microorganisms in food. Trends in Food Science \& Technology 5(2):42-49.

Human Microbiome Project Consortium. 2012. Structure, function and diversity of the healthy human microbiome. Nature 486(7402):207-14.

Karsten, R. 1935. The head-hunters of western Amazonas: the life and culture of the Jibaro Indians of eastern Ecuador and Peru. Societas Scientiarum. Helsinki, Finland.

Kostinek, M., Specht, I., Edward, V. a, Pinto, C., Egounlety, M., Sossa, C., Mbugua, S., Dortu, C., Thonart, P., Taljaard, L., et al. 2007. Characterisation and biochemical properties of predominant lactic acid bacteria from fermenting cassava for selection as starter cultures. International journal of food microbiology 114(3):342-51.

Kostinek, M., Specht, I., Edward, V. a, Schillinger, U., Hertel, C., Holzapfel, W. H., \& Franz, C. M. P. 2005. Diversity and technological properties of predominant lactic acid bacteria from fermented cassava used for the preparation of Gari, a traditional African food. Systematic and applied microbiology 28(6):527-40.

Kravtsov, E. G., Yermolayev, A. V, Anokhina, I. V, Yashina, N. V, Chesnokova, V. L., \& Dalin, M. V. 2008. Adhesion characteristics of lactobacillus is a criterion of the probiotic choice. Bulletin of Experimental Biology and Medicine 145(2):232-234.

Kricher, J. 1999. A Neotropical Companion. Princeton University Press.

Lebeer, S., Vanderleyden, J., \& De Keersmaecker, S. C. J. 2008. Genes and molecules of lactobacilli supporting probiotic action. Microbiology and Molecular Biology Reviews : MMBR, 72(4), 728-64

Lei, V., Amoa-Awua, W. K., \& Brimer, L. 1999. Degradation of cyanogenic glycosides by Lactobacillus plantarum strains from spontaneous cassava fermentation and other microorganisms. International journal of food microbiology 53(2-3):169-84. 
Liebert, M. A., Snodgrass, J. J., Madimenos, F. C., Cepon, T. J., Blackwell, A. D., \& Sugiyama, L. S. 2013. Implications of market integration for cardiovascular and metabolic health among an indigenous Amazonian Ecuadorian population. Annals of Human Biology 40(3):228-242.

Linnenbrink, M., Wang, J., Hardouin, E. a, Künzel, S., Metzler, D., \& Baines, J. F. 2013. The role of biogeography in shaping diversity of the intestinal microbiota in house mice. Molecular ecology 22(7):1904-1916.

Luedeking, R., \& Piret, E. L. 1959. A kinetic study of the lactic acid fermentation. Batch process at controlled $\mathrm{pH}$. Journal of Biochemical and Microbiological Technology and Engineering 1(4):393-412.

Makarova, K., Slesarev, A., Wolf, Y., Sorokin, A., Mirkin, B., Koonin, E., Pavlov, A., Pavlova, N., Karamychev, V., Polouchine, N., Shakhova, V., Grigoriev, I., Lou, Y., Rohksar, D., Lucas, S., Huang, K., Goodstein, D. M., Hawkins, T., Plengvidhya, V., Welker, D., Hughes, J., Goh, Y., Benson, A., Baldwin, K., Lee, J.-H., Díaz-Muñiz, I., Dosti, B., Smeianov, V., Wechter, W., Barabote, R., Lorca, G., Altermann, E., Barrangou, R., Ganesan, B., Xie, Y., Rawsthorne, H., Tamir, D., Parker, C., Breidt, F., Broadbent, J., Hutkins, R., O'Sullivan, D., Steele, J., Unlu, G., Saier, M., Klaenhammer, T., Richardson, P., Kozyavkin, S., Weimer, B., Mills, D. 2006. Comparative genomics of the lactic acid bacteria. Proceedings of the National Academy of Sciences of the United States of America 103(42):15611-6.

McDade, T. W., Tallman, P. S., Madimenos, F. C., Liebert, M. A., Cepon, T. J., Sugiyama, L. S., \& Snodgrass, J. J. 2012. Analysis of variability of high sensitivity C-reactive protein in lowland Ecuador reveals no evidence of chronic low-grade inflammation. American journal of human biology : the official journal of the Human Biology Council 24(5):675-81.

McGee, H. 2013. Chemistry: A festive ferment. Nature 504(7480):372-374.

Moseley, M. E., Nash, D. J., Williams, P. R., DeFrance, S. D., Miranda, A., \& Ruales, M. 2005. Burning down the brewery: establishing and evacuating an ancient imperial colony at Cerro Baul, Peru. Proceedings of the National Academy of Sciences of the United States of America 102(48):17264-71.

Orellana, J. D. Y., Santos, R. V., Coimbra, C. E. A., \& Leite, M. S. 2009. Anthropometric evaluation of indigenous Brazilian children under 60 months of age using NCHS/1977 and WHO/2005 growth curves. Jornal de Pediatria 85(2):117-121.

Piperata, B. A., Spence, J. E., Da-Gloria, P., \& Hubbe, M. 2011. The nutrition transition in amazonia: rapid economic change and its impact on growth and development in Ribeirinhos. American J of Physical Anthropology 13:1-13.

Piperno, D. R. 2011. The origins of plant cultivation and domestication in the new world tropics. Current Anthropology 52(4):453-470.

Ranadheera, R. D. C. S., Baines, S. K., \& Adams, M. C. 2010. Importance of food in probiotic efficacy. Food Research International 43(1):1-7.

Rubenstein, S. 2001. Colonialism, the Shuar Federation, and the Ecuadorian state. Environment and Planning D-Society \& Space 19:263-293.

Santos, C., Almeida, E. G. D., Melo, G. V. P. D., \& Schwan, R. F. 2012. Microbiological and physicochemical characterisation of caxiri, an alcoholic beverage produced by the indigenous Juruna people of Brazil. International journal of food microbiology 156(2):112-21.

Santos, R. V., Coimbra, C. E. A., \& Escobar, A. L. 2003. Cenários e tendências da saúde e da epidemiologia dos povos indígenas no Brasil. Epidemiologia e saúde dos povos indígenas no Brasil 13-47.

Scheirlinck, I., Van der Meulen, R., Van Schoor, A., Vancanneyt, M., De Vuyst, L., Vandamme, P., \& Huys, G. 2007. Influence of geographical origin and flour type on diversity of lactic acid bacteria in traditional Belgian sourdoughs. Applied and Environmental Microbiology, 73(19), 6262-9.

Schleheck, D., Knepper, T. P., Fischer, K., \& Cook, A. M. 2004. Mineralization of individual congeners of linear alkylbenzenesulfonate by defined pairs of heterotrophic bacteria. Applied and environmental microbiology 70(7):4053-4063.

Scott, R., \& Sullivan, W. 2008. Ecology of fermented foods. Human Ecology Review 15(1):25-31.

Spitaels, F., Wieme, A. D., Janssens, M., Aerts, M., Daniel, H.-M., Van Landschoot, A., ... Vandamme, P. 2014. The microbial diversity of traditional spontaneously fermented lambic beer. PloS One, 9(4), e95384.

Spor, A., Koren, O., \& Ley, R. 2011. Unravelling the effects of the environment and host genotype on the gut microbiome. Nature reviews. Microbiology 9(4):279-90.

Sun, H., Ma, H., Hao, M., Pretorius, I. S., \& Chen, S. 2009. Identification of yeast population dynamics of spontaneous fermentation in Beijing wine region, China. Annals of Microbiology, 59(1), 69-76. 
Suzzi, G. 2011. From wild strain to domesticated strain: the philosophy of microbial diversity in foods. Frontiers in microbiology 2(August):169.

Tetchi, F. A., Solomen, O. W., Célah, K. A., \& Georges, A. N. 2012. Effect of cassava variety and fermentation time on biochemical and microbiological characteristics of raw artisanal starter for attiéké production. Innovative Romanian Food Biotechnology 10(2006):40-47.

Turpin, W., Humblot, C., Noordine, M. L., Thomas, M., \& Guyot, J. P. 2012. Lactobacillaceae and cell adhesion: genomic and functional screening. PLoS one 7(5):e38034.

Turpin, W., Humblot, C., Thomas, M., \& Guyot, J.P. 2010. Lactobacilli as multifaceted probiotics with poorly disclosed molecular mechanisms. International Journal of Food Microbiology 143(3):87-102.

Van Hylckama Vlieg, J. E. T., Veiga, P., Zhang, C., Derrien, M., \& Zhao, L. 2011. Impact of microbial transformation of food on health: from fermented foods to fermentation in the gastro-intestinal tract. Current opinion in biotechnology 22(2):211-9.

Westby, A., Reilly, A., \& Bainbridge, Z. 1997. Review of the effect of fermentation on naturally occurring toxins. Food Control 8(5-6):329-339.

World Health Organization. 2011. Causes of death 2008 summary tables. WHO subregions by country. Health Statistics and Informatics Department, World Health Organization. Geneva, Switzerland.

Yang, Y. J., \& Sheu, B. S. 2012. Probiotics-containing yogurts suppress Helicobacter pylori load and modify immune response and intestinal microbiota in the Helicobacter pylori-infected children. Helicobacter 17(4):297-304. 


\section{Figure 1}

All chicha samples were dominated by Lactobacillus spp.

OTU predicted identities are from a manual BLAST search against the NCBI 165 isolate database. We found ten OTUs with greater than $1 \%$ relative abundance. This barplot shows the relative abundance (\%) of ten most common bacteria isolates for each sample. Up to three independent batches were sampled for each house (e.g. $\mathrm{H} 1 \mathrm{a}-\mathrm{H} 1 \mathrm{c})$. Eleven samples were analyzed from Village 1 and three from Village 2.

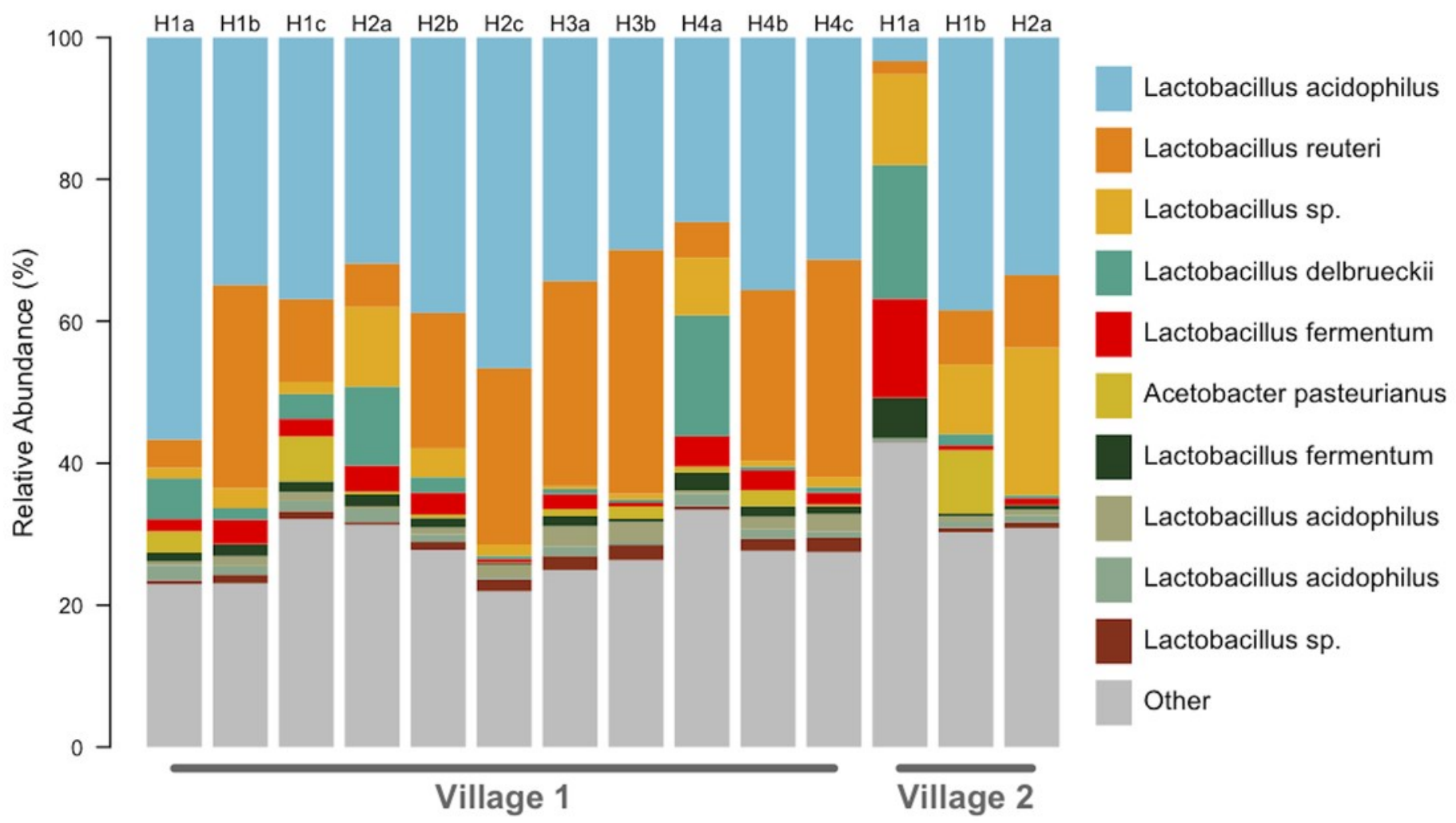




\section{Figure 2}

All chicha samples were dominated by Lactobacillus spp.

We report the NCBI accession number and the environment where isolates with the closest match to our OTUs were identified. Many of these Lactobacillus species were also identified in the human intestinal tract. Lactobacillus acidophilus and Lactobaccillus reuteri make up $51 \%$ of all OTUs in our rarified chicha samples. Collectively, these ten OTUs account for $71 \%$ cumulative abundance for all samples. "Unknown" samples had no match above $97 \%$ similarity to an existing NCBI submission.

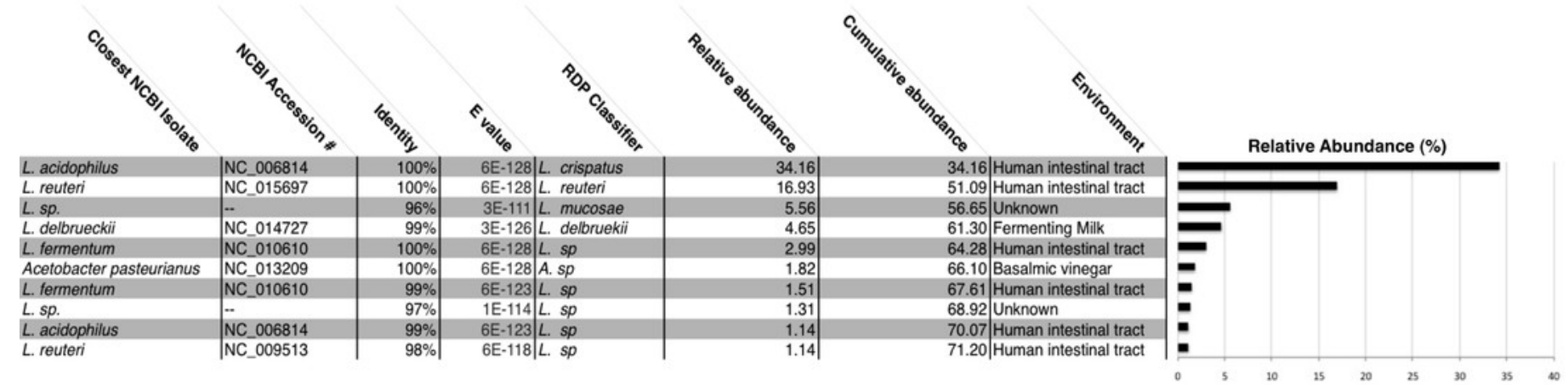




\section{Figure 3}

Chicha from the same village contain more shared OTUs

We counted shared OTUs between every possible combination of chicha samples. The average number of matching OTUs between samples that are paired within the same village was significantly higher than those paired from different villages. We considered chicha samples from different batches within the same house as independent since there was no significant difference by house. They are grouped together in this figure for visualization purposes.

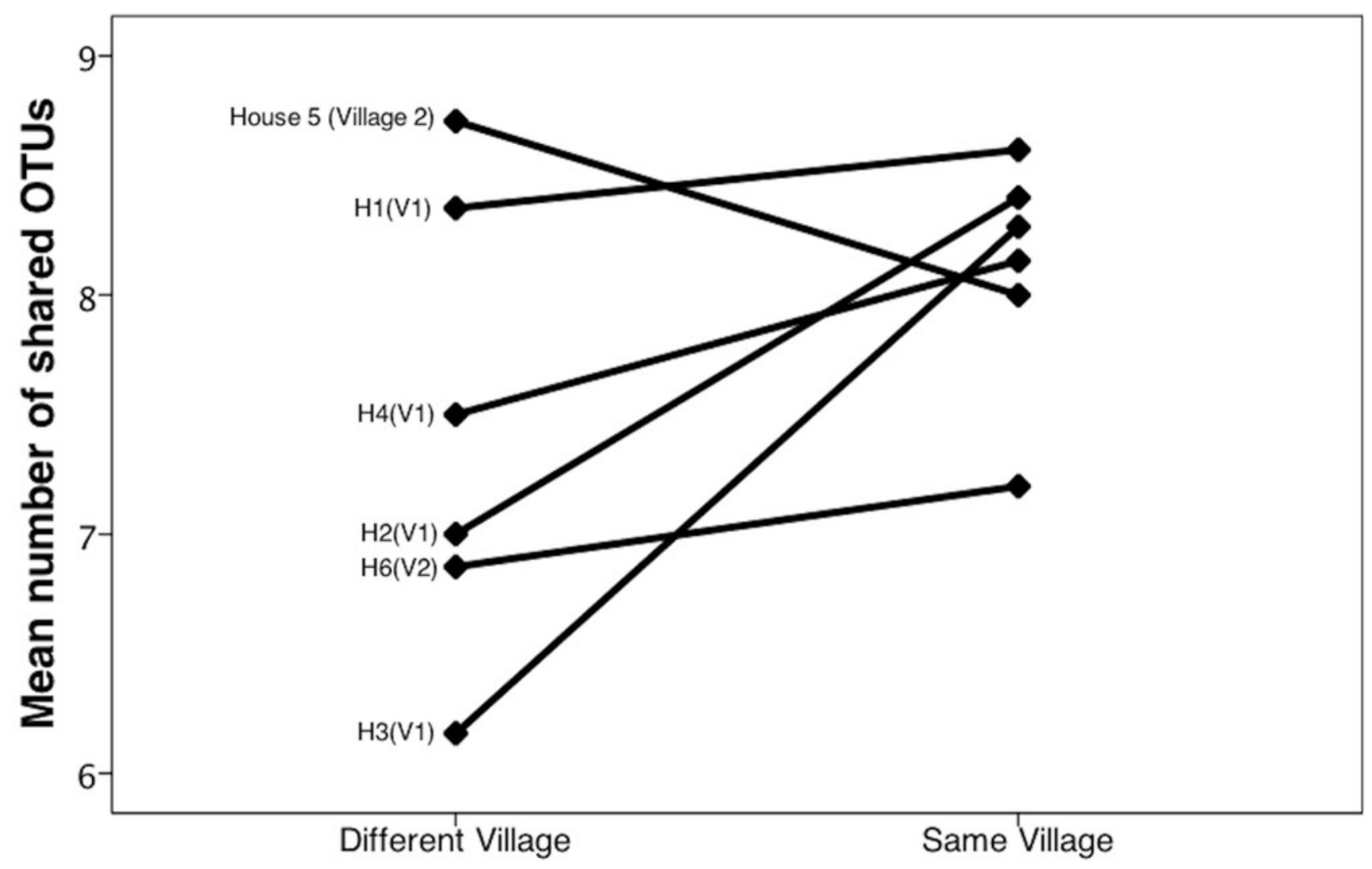




\section{Figure 4}

Principle Coordinate Analysis by Village

A PERMANOVA (Adonis) on an unweighted UniFrac dissimilarity matrix shows significant differences in bacterial populations when grouped by village $\left(F_{1,12}=1.11, R^{2}=0.08 ; p=\right.$ 0.038). While several of the samples from Village 1 are closely clustered those from Village 2 are relatively more spread out, suggesting higher variance could partially explain the significant results. More samples, evenly distributed between villages, will likely be needed to better understand the extent and pattern of site-specific differences. 
PCoA - PCl vs PC3

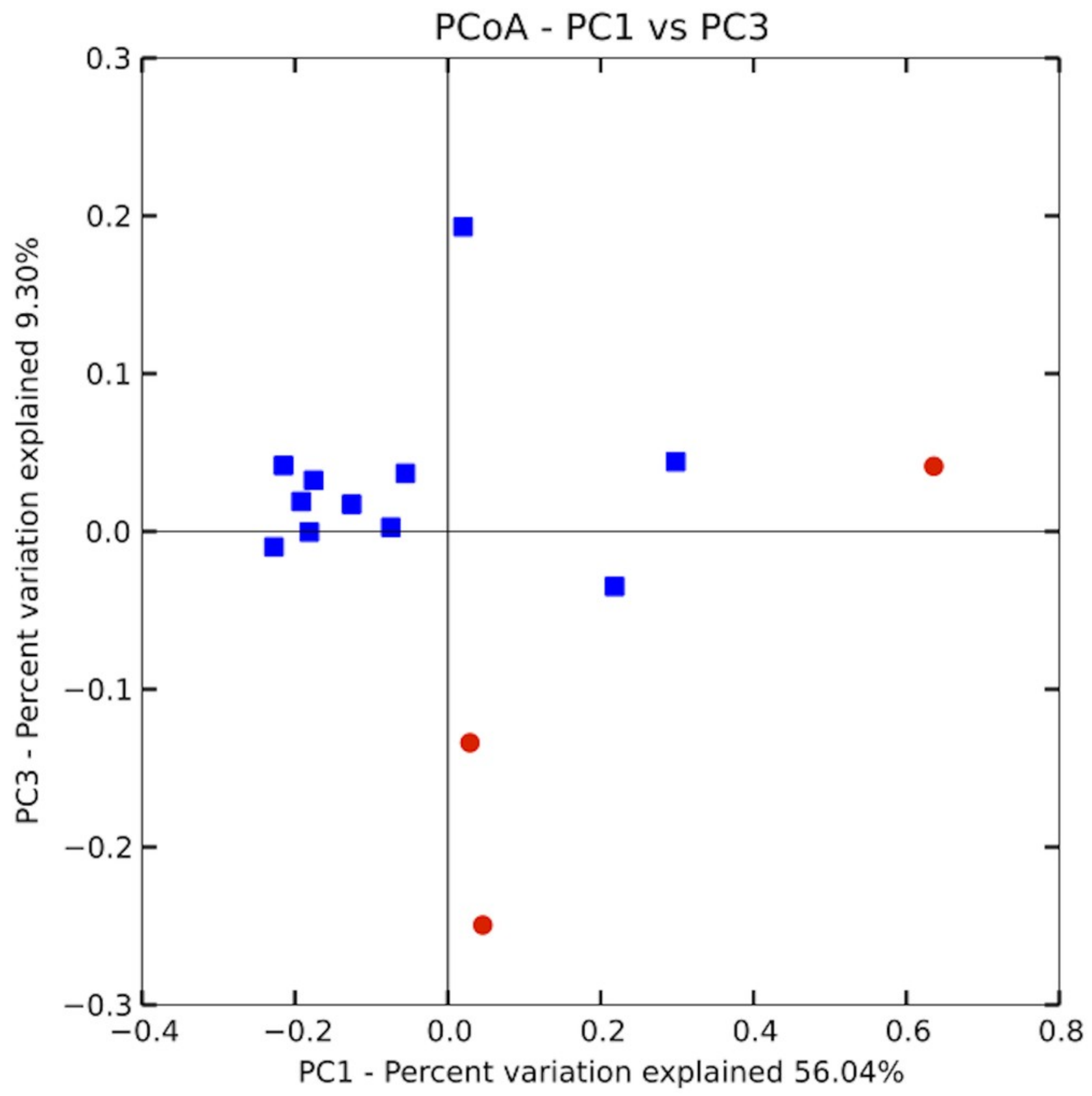




\section{Figure 5}

Conceptual model of microbial exchange between human cultivators and a locally distinct ferment

Spontaneous fermentation is an ecological phenomenon driven by distance-limited dispersal, human- mediated selection, and stochastic succession that may explain geographically diversified lactic acid fermentation. Over many generations, this process can be considered a process of microbial domestication if microbe assemblages are consistently distinct. 


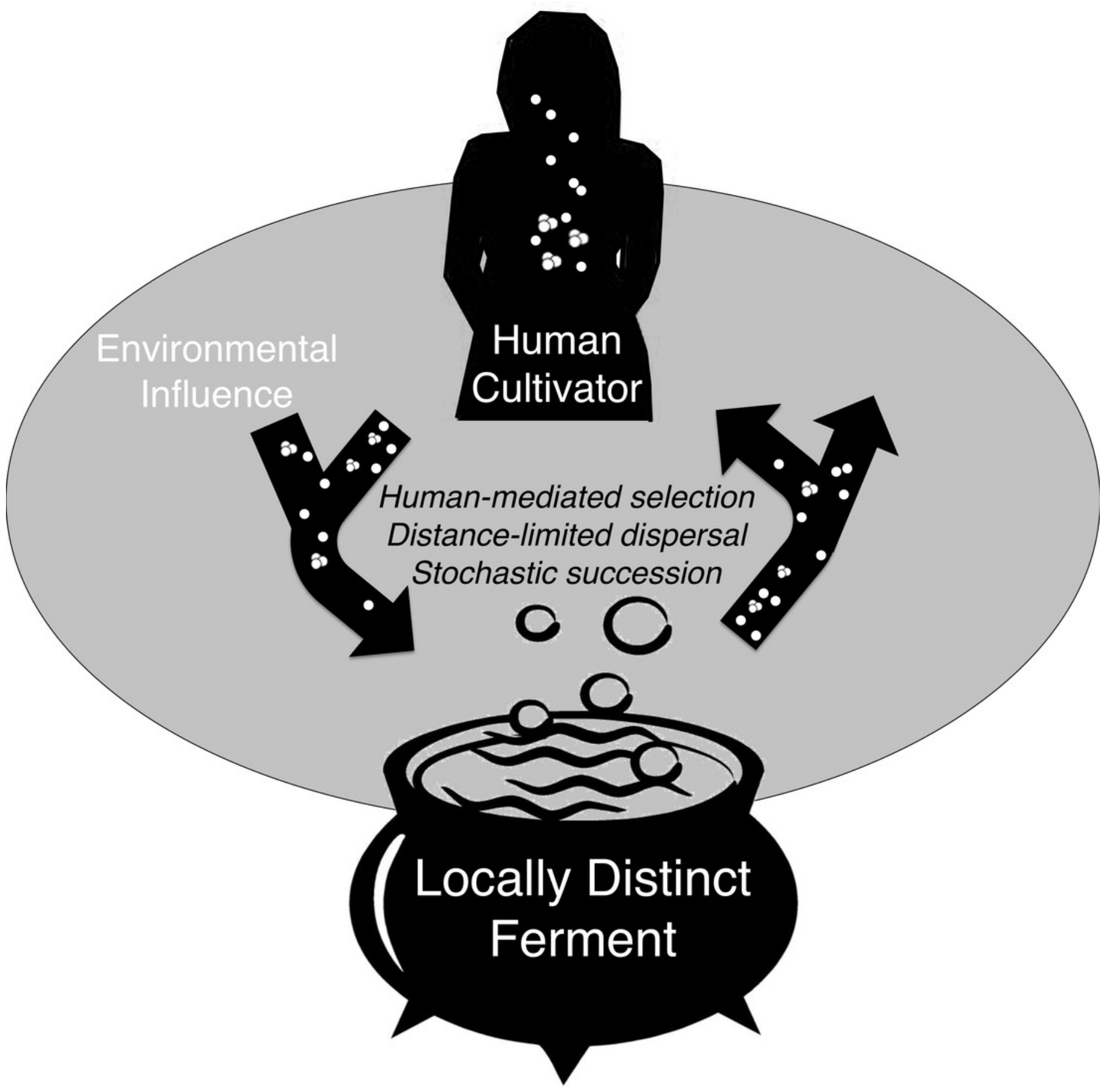

